\title{
Prospects of the use of prebiotics in broiler poultry farming as an alternative to antibiotics
}

\author{
Aleksei Reznichenko ${ }^{1}$, Liudmila Reznichenko $^{1}$, Vasilij Dorozhkin ${ }^{2}$, Sergej Noskov $^{3}$, Svetlana Vodianitskaia $^{1}$ \\ ${ }^{1}$ Belgorod State Agricultural University named after V. Gorin, 1, Vavilova str., Mayskii settlement, Belgorod, 308503, Russia \\ 2 All-Russian Research Institute of Veterinary Sanitation, Hygiene and Ecology - branch of All-Russian Research Institute of \\ Experimental Veterinary Medicine named after K.I. Scriabin and Ya.R. Kovalenko of the Russian Academy of Sciences, 5, \\ Zvenigorodskoe highway, Moscow, 123022, Russia \\ ${ }^{3}$ Belgorod Interregional Veterinary Laboratory, 32, Studencheskaya st., Belgorod, 308023, Russia
}

\begin{abstract}
The uncontrolled use of antibacterial drugs resulted in a wide spread of forms of microorganisms resistant to them. The resistance of most bacteria to one degree or another is observed in relation to almost all existing antibiotics, which led to a significant decrease in the effectiveness of their use not only in veterinary medicine but also in medicine. Therefore, an important task which veterinary service faces is the use of alternative antibacterial drugs. Thus, the development and use of prebiotics in the food of poultry for complete or partial replacement of antibiotics is considered as a new direction of modern scientific research. The authors were the first who studied the effect of the heteropolysaccharides "raspol" and "vetelac" on the organism of broiler chickens. A high pharmacological effect of both drugs was established with a clear advantage of raspol, the use of which, against the background of the absence of antibiotics, had a positive effect on the growth and viability of poultry and caused an increase in the natural resistance of organisms. Thus, prebiotic raspol can be used as an alternative to antibacterial agents in broiler poultry farming. This drug is recommended for the give to broiler chickens with water at the rate of $0.6 \mathrm{~g} / \mathrm{kg}$ of body weight starting from 7 days of age for 10 days.
\end{abstract}

\section{Introduction}

The concept of prebiotics is relatively new in the science of functional nutrition and continues to develop using advances in molecular genetics, metagenomics, metabolomics and analytical chemistry. New methods can help understand the mechanisms of action and develop a generally accepted definition of prebiotics. The definition of prebiotics accepted in scientific community is necessary for the development of standards both in individual countries and internationally, as well as for the provision of information among a wide range of stakeholders, including producers and consumers of prebiotics [1-3].

The triad "resistant - fermentation - selective stimulation" was initially attributed to the main criteria for the selection of prebiotics, i.e. resistance to the acidic environment of stomach, enzymes in the upper digestive tract and adsorption in small intestine and fermentability by intestinal microflora with selective stimulation of growth and/or activity of beneficial intestinal bacteria [4, 5].

Prebiotics can be classified according to several criteria such as nature and structure, origin and sources of raw materials, method of production and area of application. However, the main criterion is the chemical structure of prebiotic molecules, which determines their resistance to digestion in digestive tract and the ability to ferment by certain groups of intestinal bacteria.

The classic prebiotics, the effectiveness of which has been proven by scientific research, include fructans, galactans and lactulose. In some publications, in addition to the above mentioned substances, mannanooligosaccharides, gluco-oligosaccharides, pectooligosaccharides, libiozo-oligosaccharides, N-cetylchitooligosaccharides, heteropolysaccharides, gums, derivatives of resistant starch oligosaccharides etc are considered as prebiotics.

From the point of view of the practical implementation of the concept of prebiotics in Russia, a promising direction is the development of new costeffective methods of their production, as well as the creation of technologies for the most popular food products using prebiotics and synbiotics, designed to maintain normal intestinal microbiota and prevent diseases associated with its disorders. [7].

A new direction of modern scientific research is the development and use of prebiotics in feeding farm animals (poultry) as an alternative to antibacterial drugs, since the entry of domestic agricultural products to the foreign market provides for the absence of antibacterial drugs in products and raw materials of animal origin [8$10]$.

\footnotetext{
* Corresponding author: reznichenko6531@gmail.com
} 
As it is known, the nutrition of the saprophytic microflora of the intestine of farm animals (poultry) and its normal functioning fundamentally depends on the supply of polysaccharides to it, which, under the action of the intestinal microflora, undergo fermentation with the formation of short-chain fatty acids (propionic, butyric, acetic), which in turn have a pronounced antiinflammatory and anticarcinogenic effect [11].

It is proven that decrease in the $\mathrm{pH}$ level in the intestine due to bacteria that maintain the level of lactic acid, reduces the number of enteropathogens. The low $\mathrm{pH}$ and healthy villus structure significantly improves calcium absorption (47\% to 55\%). This leads to improved egg shell quality in poultry and a stronger skeleton of young animals.

It is found that the pathogenic microflora destroys the villi in intestine, which absorb the nutrients and water necessary for the growth and development of animals. Therefore, a decrease in the number of pathogens allows the villi to develop fully, which leads to an increase in the absorbing surface of the intestine, which, in turn, reduces the need for antibiotic use [12].

Our developments are aimed to replace antibacterial drugs in the diets of poultry with other substances that are absolutely harmless to human body, i.e. prebiotics.

The research purpose is to study the effect of the prebiotics "Raspol" and "Vetelac" on the organism of broiler chickens in order to offer these drugs as an alternative to antibacterial ones in the diets of poultry.

\section{Materials and methods}

The research was performed at the Department of Morphology, Physiology, Infectious and Invasive Pathology of Belgorod State Agrarian University. The study of the drug was carried out on broiler chickens. The nature of the effect of drugs on the body of the bird was assessed by the indicators of natural resistance. We took into account the viability of livestock and average daily gains and determined the quality of meat.
The formation of groups was carried out according to the principle of analogues. At the same time, the possibility of the use of "Raspol" and "Vetelac" was studied as an alternative to antibacterial drugs in the diets of broiler chickens.

Raspol is a polysaccharide of plant origin. It is a yellowish-white powder. It has a weak characteristic odor and after dissolving it forms a viscous and jelly-like consistency.

Vetelac is a polysaccharide that contains a balanced set of lactulose (at least 50\%), lactose and other carbohydrates.

Blood was taken from the axillary vein. The activity of lysozyme in blood serum was determined by the nephelometric method according to Dorofeychuk [13], phagocytic activity was determined by counting phagocytic neutrophils from 100 cells, bactericidal activity of blood serum was determined according to I.M. Karput [14].

After slaughter, the quality of poultry meat was assessed. At the same time, sampling and organoleptic research of meat was carried out in accordance with GOST R 51944 - 2002 [16], physical and chemical research was carried out in accordance with GOST 31470-2012 [15]

The digital material obtained in all experiments was subjected to statistical processing on a personal computer according to the generally accepted methods of variation statistics with the calculation of the Student's argument (td). The difference between the compared values was considered significant at $\mathrm{p} \leq 0,05$.

\section{Test results and discussion}

In order to conduct research according to the principle of analogs, 6 groups of broiler chickens of the Arbor Aikers cross of day-old age with 40 heads in each were formed. The experiment scheme is presented in Table 1.

Table 1. Scheme of the experiment on broiler chickens

\begin{tabular}{|c|c|c|c|}
\hline Groups & Heads & Used drugs & Dose \\
\hline 1 - control & 40 & Basic diet (BD) & - \\
\hline 2 - experimental & 40 & BD (without antibacterial drugs) & - \\
\hline 3 - experimental & 40 & BD + raspol & $0.6 \mathrm{~g} \mathrm{per} \mathrm{kg} \mathrm{of} \mathrm{body} \mathrm{weight}$ \\
\hline $4-$ experimental & 40 & BD (without antibacterial drugs) + raspol & $0.6 \mathrm{~g} \mathrm{per} \mathrm{kg} \mathrm{of} \mathrm{body} \mathrm{weight}$ \\
\hline $5-$ experimental & 40 & BD + vetelac & $0.1 \mathrm{ml}$ per $1 \mathrm{~kg}$ of body weight \\
\hline $6-$ experimental & 40 & BD (without antibacterial drugs) + vetelac & $0.1 \mathrm{ml} \mathrm{per} 1 \mathrm{~kg}$ of body weight \\
\hline
\end{tabular}

The first group is the control one. The second, third, fourth, fifth and sixth are experimental ones. The chickens of the control, $3^{\text {rd }}$ and $5^{\text {th }}$ experimental groups had a diet according to the scheme adopted in the farm with the use of all antibacterial drugs (starting from 2 days of age, cypromag was added to the water at the rate of $5 \mathrm{ml}$ per $10 \mathrm{~L}$ for 5 days and this drug was used from 20 days of age with water for 5 days).

The chickens of the $2^{\text {nd }}, 4^{\text {th }}$ and $6^{\text {th }}$ experimental groups did not get antibacterial drugs. The chickens of the $3^{\text {rd }}$ and $4^{\text {th }}$ of the experimental groups, starting from 7 days of age had raspol added to the water at the rate of $0.6 \mathrm{~g} / \mathrm{kg}$ of body weight for 10 days. The chickens of the $5^{\text {th }}$ and $6^{\text {th }}$ experimental groups received vetelac with water at a dose of $0.1 \mathrm{ml} / \mathrm{kg}$ of body weight for 20 days.

As a result of the conducted studies, the increase in the average daily gain of poultry in the $3^{\text {rd }}, 4^{\text {th }}$ and $5^{\text {th }}$ experimental groups and a significant decrease in the $2^{\text {nd }}$ group were found (Table 2). 
At the same time, the highest viability of the poultry was in the $3^{\text {rd }}$ experimental group $(95.0 \%)$, where the poultry was given raspol against the background of the use of antibacterial drugs. As for the $4^{\text {th }}$ experimental group, where the raspol was used in the absence of antibiotics in the scheme of antiepizootic measures, the viability was $92.5 \%$. The same viability was in the control group. In the $5^{\text {th }}$ and $6^{\text {th }}$ experimental groups, after vetelac application, the viability of birds was 92.5 and $90 \%$, respectively. As for the $2^{\text {nd }}$ experimental group, where no drugs were used, the lowest viability $(82.5 \%)$ and the lowest average daily gains $(53.4 \mathrm{~g})$ were noted here.

Table 2. Result of experiment of prebiotics in broiler chickens

\begin{tabular}{|c|c|c|c|c|}
\hline \multirow{2}{*}{ Groups } & \multicolumn{4}{|c|}{ Indicators } \\
\cline { 2 - 5 } & Viability\% & $\begin{array}{c}\text { Average weight of 1 head at the end } \\
\text { of the experimental period (38 days) }\end{array}$ & $\begin{array}{c}\text { Average daily } \\
\text { gains, g }\end{array}$ & $\begin{array}{c}\text { Feed costs per } 1 \mathrm{~kg} \\
\text { gain, kg }\end{array}$ \\
\hline 1 - control & 92,5 & 2478 & 65,0 & 1,69 \\
\hline 2 - experimental & 82,5 & 1896 & 53,4 & 1,72 \\
\hline 3 - experimental & 95,0 & 2500 & 66,8 & 1,67 \\
\hline 4 - experimental & 92,5 & 2478 & 65,6 & 1,68 \\
\hline 5 - experimental & 92,5 & 2480 & 65,2 & 1,69 \\
\hline 6 - experimental & 90 & 2444 & 64,6 & 1,7 \\
\hline
\end{tabular}

The autopsy of dead birds of the $1^{\text {st }}$ and $2^{\text {nd }}$ experimental groups indicated the presence of colibacillosis. The diagnosis was confirmed by laboratory tests. In chickens of the $3^{\text {rd }}, 4^{\text {th }}, 5^{\text {th }}$ and $6^{\text {th }}$ experimental groups, the diagnosis of colibacillosis was not confirmed. Autopsy revealed hepatosis and enteritis.

Thus, the studies indicate a high pharmacological effect of prebiotics, in particular raspol, the use of which, against the background of the absence of antibiotics, had a positive effect on the growth and safety of poultry. That allows using raspol as an alternative to antibacterial drugs in the diet of broiler chickens.

During the study of natural resistance, an increase in the bactericidal activity of blood serum and the phagocytic activity of pseudo-eosinophils from the use of all studied drugs was established (Table 3).

Table 3. Indicators of natural resistance of broiler chickens, $n=20(M \pm m)$

\begin{tabular}{|l|l|l|l|}
\hline \multirow{2}{*}{\multicolumn{1}{|c|}{ Groups }} & \multicolumn{3}{c|}{ Indicators } \\
\cline { 2 - 4 } & \multicolumn{1}{c|}{$\begin{array}{c}\text { Bactericidal } \\
\text { activity, } \%\end{array}$} & $\begin{array}{c}\text { Phagocytic } \\
\text { activity, } \%\end{array}$ & $\begin{array}{c}\text { Lysozyme } \\
\text { activity, } \%\end{array}$ \\
\hline 1- control (BD) & $32,76 \pm 1,49$ & $36,23 \pm 1,42$ & $11,63 \pm 1,17$ \\
\hline 2-experimental (BD without antibiotics) & $29,28 \pm 1,54$ & $35,43 \pm 1,66$ & $11,14 \pm 1,33$ \\
\hline 3-experimental (BD + raspol) & $40,88 \pm 1,53^{*}$ & $45,87 \pm 1,58^{*}$ & $12,12 \pm 1,29$ \\
\hline $\begin{array}{l}\text { 4-experimental } \\
\text { (BD without antibiotics + raspol) }\end{array}$ & $40,22 \pm 1,76^{*}$ & $45,39 \pm 1,52^{*}$ & $13,14 \pm 0,21$ \\
\hline 5-experimental (BD + vetelac) & $39,27 \pm 1,56^{*}$ & $44,37 \pm 1,68^{*}$ & $12,79 \pm 1,36$ \\
\hline $\begin{array}{l}\text { 6-experimental } \\
\text { (BD without antibiotics + vetelac) }\end{array}$ & $38,21 \pm 1,71^{*}$ & $43,22 \pm 1,63^{*}$ & $13,111 \pm 1,19$ \\
\hline
\end{tabular}

$* \mathrm{p}<0,05$

Thus after the application of raspol in the $3^{\text {rd }}$ experimental group, there was a significant increase in the bactericidal activity of blood serum and the phagocytic activity of pseudo-eosinophils by 24.8 and $26.6 \%$, respectively, in comparison with the control. In the $4^{\text {th }}$ experimental group, after the use of this drug, but with the complete exclusion of antibiotics, these indicators of natural resistance also increased by 22.7 and $25.3 \%$.

After feeding vetelac in the $5^{\text {th }}$ experimental group, there was an increase in the bactericidal activity of blood serum and phagocytic activity of pseudo-eosthnophils by 19.9 and $22.45 \%$, respectively, compared to the control one. In the $6^{\text {th }}$ experimental group, after the use of this drug, but with the complete exclusion of antibiotics, these indicators of natural resistance also increased by
$16.6 \%$ and $19.3 \%$, respectively, in all cases the difference with the control was statistically confirmed ( $\mathrm{p}$ $<0.05)$.

At the end of the experimental period, poultry were slaughtered and a veterinary and sanitary examination of meat and internal organs was carried out.

The veterinary and sanitary assessment of the internal organs of chickens of the $3^{\text {rd }}, 4^{\text {th }}, 5^{\text {th }}$ and $6^{\text {th }}$ experimental groups showed that all organs were of normal color and size, without any pathological changes. All chickens had a shiny beak without damage, strong which did not bend. There was no salt deposition in their kidneys, which indicated the absence of a violation of mineral metabolism. The mucous membrane of the oral cavity was smooth, shiny, slightly moist and pale pink in color. The liver was bright brown, firm, not enlarged. The heart 
was pink, dense in consistency. There were no signs of uric acid diathesis, which indicated the normalization of protein metabolism.

As for the internal organs of the chickens of the control and the $2^{\text {nd }}$ experimental group, $10 \%$ of the carcasses had liver damage. Their livers were of a friable, pale yellow consistency. Heart damage was also observed. The pericardial sac was filled with a light yellow fibrinous effusion.

As it is known, the organoleptic characteristics of meat are formed from a variety of factors, the most important of which is the biochemical processes occurring in the tissues of meat after slaughter, which determine the degree of ripening of products.

After 24 hours from the moment of slaughter, the carcasses of the experimental bird had a dry crust of drying, whitish-yellow in color, the muscles were dense, elastic consistency, slightly moist, the pectorals were white-pink, the legs were red, typical for this type of bird. The smell from the surface and in the depth of the cut was specific, characteristic of fresh meat. The subcutaneous and internal fat of broilers, both with the inclusion of the additive in the diet and without its use, was pale yellow in color, without odors and tastes, transparent in the molten state. During the cooking test, the broth was clear and aromatic. On the surface of the broth, fat collected in large droplets.

However, the carcasses of chickens in the control and $2^{\text {nd }}$ experimental groups had poor bleeding.

Physicochemical indicators of meat are presented in Table 4.

Table 4. Physicochemical indicators of broiler chicken meat, $n=20(M \pm m)$

\begin{tabular}{|l|c|c|c|c|c|c|}
\hline \multicolumn{1}{|c|}{ Indicators } & \multicolumn{5}{|c|}{ Groups } \\
\hline \multicolumn{1}{|c|}{$\mathrm{PH}_{\mathrm{H}}$} & 1-control & 2-experimental & 3-experimental & 4-experimental & 5 -experimental & 6 -experimental \\
\hline Reaction with benzidine & $6,84 \pm 0,06$ & $7,01 \pm 0,05$ & $6,14 \pm 0,04$ & $5,97 \pm 0,09$ & $5,83 \pm 0,07$ & $6,14 \pm 0,09$ \\
\hline $\begin{array}{l}\text { Acid number of fat, mg } \\
\text { KOH }\end{array}$ & $0,96 \pm 0,07$ & $0,93 \pm 0,06$ & $0,92 \pm 0,08$ & $0,91 \pm 0,06$ & $0,95 \pm 0,07$ & $0,94 \pm 0,04$ \\
\hline $\begin{array}{l}\text { Acidity-oxidizability } \\
\text { coefficient }\end{array}$ & $0,42 \pm 0,08$ & $0,43 \pm 0,04$ & $0,56 \pm 0,06$ & $0,57 \pm 0,08$ & $0,55 \pm 0,06$ & $0,50 \pm 0,05$ \\
\hline Formol reaction & doubtful & doubtful & negative & negative & negative & negative \\
\hline
\end{tabular}

Analyzing the physic-chemical parameters of poultry meat, it is necessary to note that $\mathrm{pH}$ of the muscle tissue of chickens of the $3^{\text {rd }}, 4^{\text {th }}, 5^{\text {th }}$ and $6^{\text {th }}$ experimental groups corresponds to matured and pure.

From the data in the table it can be seen that the acidity-oxidizability coefficient of the meat of these chickens was in the range of $0.50-0.56$. The reaction with benzidine in these groups was positive; the formol reaction was negative, which indicated that the meat was from healthy poultry.

While in the meat of chickens of the control and the $2^{\text {nd }}$ experimental group, the acidity-oxidizability coefficient was $0.42-0.43$, the reaction with benzidine and the formol test were doubtful, which indicated that the poultry was sick before slaughter

\section{Conclusion}

Thus, the studies show that raspol and vetelac increase the natural resistance of organisms and, as a result, increase the average daily gain and viability of broiler chickens. Moreover, the complete exclusion of antibacterial drugs from the diet of a bird does not have a negative effect on their bodies. These drugs have a positive effect on the quality of the obtained products.

\section{Practical proposals}

As an alternative to antibacterial drugs, prebiotic raspol is proposed. This drug is recommended to feed broiler chickens with water at the rate of $0.6 \mathrm{~g} / \mathrm{kg}$ of body weight starting from 7 days of age for 10 days.

\section{References}

1. N. Binns, Probiotics, prebiotics and the gut microbiota. ILSI Europe Concise Monographs Series (Washington, 2013) pp. 1-32.

2. R.W. Hutkins, J.A. Krumbeck, L.B. Bindels et al., Prebiotics: why definitions matter, Curr. Opin. Biotechnol., 37, 1-7 (2016).

3. K. Venema, A.P. do Carmo, Probiotics and Prebiotics: Current Research and Future Trends (The Netheralnds and Instituto Federal do Espirito Santo, Soteco, Brazil: Caister Academic Press, 2015) 508 p.

4. G.R. Gibson, M.B. Roberfroid, Dietary modulation of the human colonic microbiota: Introducing the concept of prebiotics, J. Nutr., 125, 1401-1412 (1995).

5. G. Reid, M.E. Sanders, H.R. Gaskins et al., New scientific paradigms for probiotics and prebiotics, J. Clin. Gastroenterol., 37, 105-118 (2003).

6. A.G. Khramtsov, S.A. Ryabtseva, R.O. Budkevich, et al., Prebiotics as functional food ingredients: terminology, selection and comparative assessment criteria, classification, Nutrition issues, 87(1), 5-17 (2018).

7. L. Reznichenko, A. Gorbach, New immune response modulator for poultry, BIO Web Conf., 27 (2020). 
8. A.A. Gorbach, L.V. Reznichenko, A.A. Reznichenko, The use of immunostimulants to exclude antibiotics in broiler poultry farming, Veterinary and feeding, 4, 45-48 (2018).

9. M.M. Goryacheva, An alternative to antibiotics, Poultry and poultry products, 1, 16-19 (2013).

10. N.M. Kazachkova, S.R. Ishbulatova, G.K. Duskaev, An alternative to antibiotic therapy in animal husbandry - the use of medicinal plants, International student scientific bulletin, 4, 3 (2017).

11. I.I. Murzin, Russian market of prebiotics: food ingredients business (2011). Retrieved from: http://bfi-

online.ru/aviews/index.html?msg (date of reference 09.10.16).

12. A.A. Reznichenko, The use of prebiotics in broiler poultry as an alternative to antibacterial drugs,
Conference on Agribusiness, Environmental Engineering and Biotechnologies (AGRITECH2019), p. 50 (2019).

13. V.G. Dorofeychuk, Determination of lysozyme activity by nephelometric method, Laboratory business, 1, 67 (1968).

14. I.M. Karput, Immunology and immunopathology of diseases of young animals (Urajay, Minsk, 1993) $288 \mathrm{p}$.

15. GOST R 51944 - 2002 "Poultry meat. Methods for determining organoleptic parameters, temperature and weight" according to technical conditions.

16. GOST 31470-2012 "Poultry meat, by-products and semi-finished products from poultry meat. Methods of organoleptic and physical and chemical research." 